\title{
Sensitivity of Alvarado Score among the Suspected Appendicitis Patients at a Tertiary Level Teaching Hospital
}

\author{
Md. Shamsuzzaman*1, Md. Alamgir Hossain Sikder², Quazi Sabran Uddin Ahmed³, \\ Shyamol Chandra Banik ${ }^{4}$, Kartick Chanda Shaha ${ }^{5}$
}

\section{Abstract}

Introduction: The aim of this study was to screening the Sensitivity of Alvarado score among the hospitalized suspected appendicitis patients at Dhaka National Medical College Hospital for determine the diagnostic accuracy. Materials and Methods: It was an observational type of descriptive study, conducted in the Dhaka National Medical College Hospital, Dhaka, during the study period of July 2015 to December 2015. The study was approved by the institutional ethical committee. Results: Most of the appendicitis patients belonged to the between 21-30 years which was 64 (32\%). Male appendicitis patients (52\%) are more than the female patients (48\%). Majority of the patients (69\%) complains pain occurs in the Right iliac fossa. The sensitivity of Alvarado scores was $81.60 \%$, specificity 74.58\%, accuracy 79.35\%, positive and negative predictive values were $87.18 \%$ and $65.67 \%$ respectively. Conclusion: Alvarado score has more specificity.

Keywords: Alvarado score, Appendicitis patients.

Number of Tables: 06; Number of Figure: 01; Number of References: 12; Number of Correspondence: 05.

*1. Corresponding Author:

Dr. Md. Shamsuzzaman

Assistant Professor

Department of Surgery

Dhaka National Medical College, Dhaka.

2. Dr. Md. Alamgir Hossain Sikder

Associate Professor

Department of Surgery

Dhaka National Medical College, Dhaka.

3. Dr. Major Quazi Sabran Uddin Ahmed

Classified Surgical Specialist

Boarder Guard Hospital, Dhaka.

4. Dr. Shyamol Chandra Banik

Assistant Professor

Department of Physiology

Dhaka National Medical College, Dhaka.

5. Dr. Kartick Chanda Shaha

Assistant Professor

Department of Pharmacology

Dhaka National Medical College, Dhaka.

\section{Introduction:}

Acute appendicitis is the most common cause of 'Acute Abdomen' in young adults. Appendicectomy is the treatment of choice and it is the most frequently performed urgent abdominal surgery and is often the first major procedure performed by a surgeon in training ${ }^{1}$. Multiple scoring system have been developed for the diagnosis of acute appendicitis among which Alvarado is the most commonly used scoring system $^{2}$. However this scoring system was created in west and when applied in different environments, such as middle east and asia the sensitivity and specificity levels achieved very low ${ }^{3,4}$. According to the Alvarado score, if score 1-4: acute appendicitis very unlikely, Score 5-7: acute appendicitis probable, Score 8-10: acute appendicitis definite. The aim of this study was to screening the sensitivity of Alvarado score among the patient presented with right iliac fossa pain and who are suspected of acute appendicitis in Dhaka National Medical College Hospital for determine the diagnostic accuracy. The Alvarado score system are given below.

Table A: Alvarado appendicitis score system.

\begin{tabular}{lc}
\hline Date of assessment & \\
\hline Time of assessment & Score \\
\hline Symptoms & 1.0 \\
\hline Pain migration to RIF & 1.0 \\
Anorexia & 1.0 \\
Nausea and vomiting & \\
\hline Signs & 2.0 \\
\hline RIF tenderness & 1.0 \\
Rebound tenderness & 1.0 \\
Fever & \\
\hline Investigations & 2.0 \\
\hline Raised WBC count & 1.0 \\
Shift of WBC to left & 10 \\
Total &
\end{tabular}

Total score is achieved by adding all the score for each category

$1=$ Score 8-10: acute appendicitis definite.

$2=$ Score 5-7: acute appendicitis probable.

3 = Score 1-4: acute appendicitis very unlikely.

\section{Materials and Methods:}

It was an observational type of descriptive study, conducted in the Dhaka National Medical College Hospital, Dhaka, during the study 
period of July 2015 to December 2015. The study was approved by the institutional ethical committee. To evaluate the sensitivity of Alvarado score among the suspected appendicitis patients, a data collection sheet was prepared. Total 200 case records were studied during the study period. The data was obtained from the hospitalized patients. All filled questionnaires were entered into the computer for subsequent analysis using SPSS method version 20.1.

\section{Results:}

Table I shows mean age of the patients were $35.83( \pm 12.30)$ years, minimum age was 18 years and maximum age was 57 years. Maximum age group was between 21-30 years which was 64 (32\%).

Table-I: Age group distribution of the study population $(n=200)$.

\begin{tabular}{lll}
\hline Age in years & Frequency & Percentage (\%) \\
\hline$<20$ years & 16 & $8 \%$ \\
$21-30$ years & 64 & $32 \%$ \\
$31-40$ years & 48 & $24 \%$ \\
$41-50$ years & 30 & $15 \%$ \\
$>50$ years & 42 & $21 \%$ \\
Total & 200 & $100 \%$ \\
\hline Mean \pm SD & $35.83( \pm 12.30)$ & Range $18-57$ years \\
\hline
\end{tabular}

According to figure 1, More than half (52\%) were male patients and $48 \%$ were female patients. Male and female ratio was 1.08:1.

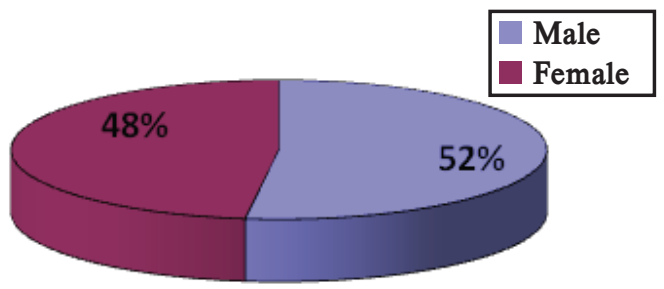

Figure-1: Sex distribution of the study population.

According to table II, in $29(14.5 \%)$ patients pain occurred at peri -umbilical region, $138(69 \%)$ patients pain occurred at Right iliac fossa and 33(16.5\%) patients pain occurred at other place.

Table-II: Site of pain of the study population $(n=200)$.

\begin{tabular}{lcc}
\hline Site of pain & Frequency & Percentage (\%) \\
\hline Peri-umbilical region & 29 & $14.5 \%$ \\
Right iliac fossa & 138 & $69 \%$ \\
Other place & 33 & $16.5 \%$ \\
\hline Total & 200 & $100 \%$
\end{tabular}

According to table III, pathological findings 136(68\%) were positive for acute appendicitis and 64(32\%) were negative for acute appendicitis.

Table-III: Histo-pathological findings of the study population $(n=200)$.

\begin{tabular}{lcc}
\hline Histopathological findings & Frequency & Percentage (\%) \\
\hline Positive for acute appendicitis & 136 & $68 \%$ \\
Negative for acute appendicitis & 64 & $32 \%$ \\
\hline Total & 200 & $100 \%$ \\
\hline
\end{tabular}

According to table IV, Majority of the patients (63.5\%) alvarado score $\geq 7$.
Table-IV: Alvarado score of the study population $(n=200)$.

\begin{tabular}{ccc}
\hline Alvarado score & Frequency & Percentage (\%) \\
\hline$<7$ & 73 & $36.5 \%$ \\
$\geq 7$ & 127 & $63.5 \%$ \\
\hline Total & 200 & $100 \%$ \\
\hline
\end{tabular}

According to table $\mathrm{V}$, sensitivity of Alvarado scores was $81.60 \%$, specificity $74.58 \%$, accuracy $79.35 \%$, positive and negative predictive values were $87.18 \%$ and $65.67 \%$ respectively.

Table-V: Performance of the diagnostic test $(n=200)$.

\begin{tabular}{cccccc}
\hline Parameter & Sensitivity & Specificity & $\begin{array}{c}\text { Positive } \\
\text { predictive value }\end{array}$ & $\begin{array}{c}\text { Negative } \\
\text { predictive value }\end{array}$ & Accuracy \\
\hline $\begin{array}{c}\text { Alvarado } \\
\text { scores }\end{array}$ & $81.60 \%$ & $74.58 \%$ & $87.18 \%$ & $65.67 \%$ & $79.35 \%$ \\
\hline
\end{tabular}

\section{Discussion:}

Acute appendicitis is one of the common causes of emergency surgery. Most of the patient presented with the right lower abdominal pain. But the diagnosis of acute appendicitis and decision to make surgery is often difficult. Because the history and presentation of these patients are variable and accurate diagnosis is not easy, but the delay in the diagnosis may cause fatal complications which in turn increase morbidity and mortality. In this present study showed mean age was $35.83( \pm 12.30)$ years, minimum age was 18 years and maximum age was 57 years. Maximum age group was between 21-30 years which was 64 (32\%). Majority $52 \%$ were male and $48 \%$ were female, male: female ratio was 1.08:1. In study of Chong et al. ${ }^{5}$ showed the mean age of the patients (92 male, 100 female) was 25.1 \pm 12.7 years. In Ismail Alnjadat I, Baha Abdallah study ${ }^{6}$ male to female ratio was $1.5: 1$ and mean age was 26.52 years. These results are consistent with other studies ${ }^{7,8}$. In our study most of the pain occurs in right illac fossa (69\%). Our study results are similar to the Nshuti et al. ${ }^{9}$ study but the percentage is not same. In their study they stated that most of the pain occurs in right iliac fossa (95\%). In this study showed sensitivity of Alvarado scores was $81.60 \%$, specificity $74.58 \%$, accuracy $79.35 \%$, positive and negative predictive values were $87.18 \%$ and $65.67 \%$ respectively. Khan et al. ${ }^{10}$ applied the Alvarado scoring system in an Asian population and only achieved a sensitivity and specificity of $59 \%$ and $23 \%$, respectively, with a negative appendicectomy rate of $15.6 \%$. The sensitivity of the Alvarado score achieved when applied in an oriental population, at the suggested cut-off threshold of 7.0, was similarly low at $50.6 \%$, but achieved a high specificity of $94.5 \%{ }^{11}$. However, this improved when the cut-off threshold was lowered to 6.0 , with a sensitivity and specificity of $88.3 \%$ and $94.5 \%$, respectively, suggesting a definite ethnic difference with regard to the Alvarado score ${ }^{11}$. Both the Alvarado and modified Alvarado scores lack parameters that have been shown to be important determinants in the diagnosis of acute appendicitis, such as age, gender and the duration of symptoms. Wani et al. ${ }^{12}$ have shown that the sensitivity and specificity of the Alvarado scoring system vary with age, gender and duration of the symptoms. 


\section{Conclusion:}

Alvarado score has more specificity. The Alvarado scoring systems vary with age, gender and duration of the symptoms. So it is not 100 percent accurate for all the patients.

\section{Conflict of Interest: None.}

\section{Acknowledgement:}

The authors are very much grateful to the entire staff of the surgery department of Dhaka National Medical College Hospital for their cooperation during the study period.

\section{References:}

1. Ashmawy. Evaluation of combined graded compression Ultrasonography with Alvarado score in the diagnosis of acute appendicitis. Alexandria Bulletin. 2006; 42(1): 29-31.

2. Kalan M, Talbot D, Cunliffe W J, Rich A J. Evaluation of the modified Alvarado score in the diagnosis of acute appendicitis: a prospective study. Ann R Coll Surg Engl. 1994; 76: 418-19.

3. Al-Hashemy AM, Seleem MI. Appraisal of the modified Alvarado score of the acute appendicitis in adults. Saudi Med J. 2004: 1229-31.

4. Khan I, Ur Rehman A. Application of Alvarado scoring system in the diagnosis of acute appendicitis. J Ayub Med Coll Abbottabad. 2005: 41-42.

5. Chong C F, Thien A, Mackie A J A, Tin A S, Tripathi S, Ahmad M A, et al. Comparison of RIPASA and Alvarado scores for the diagnosis of acute appendicitis. Singapore Med J. 2011: 34.
6. Ismail Alnjadat I, Abdallah B. Alvarado versus RIPASA score in diagnosing acute appendicitis. Rawal Medical Journal. 2013: 147-151.

7. Askarpour S, Pour FF, Rezaei SK. Accuracy of Diagnosis of Appendicitis and Its Relation to Perforation in Hospitalized Children in Surgery Department of Imam Khomeini Hospital-Ahwaz. Ann Pediatr Surg. 2008: 74-77.

8. Sulu B, Gunerhan Y, Palanci Y, Isler B, Caglayan K. Epidemiological and demographic features of appendicitis and influences of several environmental factors. Turk J Trauma Emerg Surg. 2010: 38-42.

9. Nshuti, R., Kruger, D., Luvhengo, E T. Clinical presentation of acute appendicitis in adults at the Chris Hani Baragwanath academic hospital. Int J Emerg Med. 2014; 7. https://doi.org/10.1186/1865-1380-7-12

PMid:24533851 PMCid:PMC3938026

10. Khan I, Ur Rehman A. Application of alvarado scoring system in diagnosis of acute appendicitis. J Ayub Med Coll Abbottabad. 2005: 41-44.

11. Jang SO, Kim BS, Moon DJ. Application of alvarado score in patients with suspected appendicitis. Korean $\mathbf{J}$ Gastroenterol. 2008: 27-31.

12. Wani MM, Yousaf MN, Khan MA. Usefulness of the Alvarado scoring system with respect to age, sex and time of presentation, with regression analysis of individual parameters. Internet J Surg, 2007; Available at: www. ispub.com/ journal/the_ internet_journal_of_surgery/ archive/ volume_11_number_2 .html. Accessed July 1, 2008.

https://doi.org/10.5580/d56 